\title{
Sentidos e significados atribuídos por homens ao vivido na pandemia da Covid-19
}

\author{
Meanings and perspectives of men on what they lived during the Covid-19 pandemic \\ Sentidos y significados atribuidos por hombres a lo vivido en la pandemia de Covid-19
}

Como citar este artigo:

Sousa AR, Queiroz AM, Florêncio RMS, Alves GV, Pedreira LC, Teixeira E. Meanings and perspectives of men on what they lived during the COVID-19 pandemic. Rev Esc Enferm USP. 2021;55:e03763. https://doi.org/10.1590/S1980-220X2020046403763

\section{Anderson Reis de Sousa ${ }^{1}$ \\ Aline Macêdo Queiroz ${ }^{2}$ \\ Raíssa Millena Silva Florêncio ${ }^{3}$ \\ Gilson Vieira Alves ${ }^{4}$ \\ Larissa Chaves Pedreira ${ }^{5}$ \\ Elizabeth Teixeira ${ }^{6}$}

${ }^{1}$ Universidade Federal da Bahia, Escola de Enfermagem, Salvador, BA, Brasil.

${ }^{2}$ Universidade Federal do Pará, Faculdade de Enfermagem, Belém, PA, Brasil.

${ }^{3}$ Faculdade Estácio de Alagoinhas, Alagoinhas, BA, Brasil.

${ }^{4}$ Universidade do Estado da Bahia, Salvador, BA, Brasil.

${ }^{5}$ Universidade Federal da Bahia, Salvador, BA, Brasil.

${ }^{6}$ Universidade Estadual do Amazonas, Manaus, AM, Brasil

\begin{abstract}
Objective: To understand the meanings and perspectives attributed by men to the period lived in the Covid-19 pandemic. Method: Qualitative study structured on the concepts of phenomenology, based on Heidegger's ontic interpretation, carried out with 400 men residing in Brazil. Data was produced through a form made available online. The responses were processed in the NVIVO12 software and analyzed according to the Discourse of the Collective Subject. Results: Two units of analytical meanings revealed in discourse-synthesis emerged. These units were supported by central ideas and ordered in five subunits that represent the collectivity of the investigated phenomenon. The units are: Being and being-in-the-world in the context of the pandemic-experiencing its possibilities and The vigor of the past and the present are presented as possibilities for a new future in the face of the pandemic. Conclusion: The meanings and perspectives revealed a being-there in the context of the pandemic based on themselves, with changes in the routine and feelings and willingness to new possibilities and transformations, which generated psychosocial impact and coping and care strategies in the period of the pandemic. As implications, it is necessary to have a new understanding of the man-being, as they demonstrate the need for care, and for a care that goes beyond physical health.
\end{abstract}

\section{DESCRIPTORS}

Pandemics; Covid-19; Men’s Health; Existentialism; Humanism; Nursing. 


\section{INTRODUÇÃO}

A pandemia da Covid-19 emergiu como um fenômeno complexo, real, perceptível e incerto para todas as sociedades existentes no planeta ${ }^{(1)}$. Configura-se no maior desafio sanitário do século, o qual vem provocando expressivas transformações nos modos de ser e de estar-aí das populações em seus distintos contextos. São observadas mudanças nas distintas dimensões da vida humana, considerando as relações do cotidiano, o funcionamento das cidades, assim como as alterações em hábitos, comportamentos, atitudes e práticas ${ }^{(2)}$.

A partir de um olhar baseado em gênero, a literatura científica $^{(3-5)}$ tem apontado que pessoas do sexo masculino, no geral homens cisgêneros - indivíduo que se identifica nos diversos aspectos com o seu gênero atribuído ao nascer -, têm sido mais afetadas pela pandemia da Covid-19. Esse grupo populacional apresenta elevadas taxas de infecção, manifestação mais severa da doença, com piores desfechos clínicos e maior possibilidade de transmitir a doença para as pessoas próximas ${ }^{(3)}$. Observa-se que, para além do adoecimento pela Covid-19, a pandemia provocou nessas pessoas transformações inerentes às suas (inter)subjetividades individuais, nos seus modos de relação com as pessoas e com o mundo circundante. Houve a elaboração de novos sentidos e significados desses homens para consigo mesmo, com a família e a rede de afeto, a sociedade, com o mundo e a cotidianidade do "ser-aî"(6).

Assim, profissionais de enfermagem quando bem posicionados, sensibilizados e capacitados têm total base para atuar na produção do cuidado à saúde de homens no contexto da pandemia e em cenários pós-pandêmicos. Essa atuação pode se dar no âmbito do enfrentamento dos agravos impostos pela Covid-19 e os seus impactos adjacentes, no manejo das respostas humanas afetadas nas distintas dimensões da vida, na atenção integral às necessidades específicas de saúde masculina, bem como no empoderamento sanitário e político dos sujeitos e na ampliação do letramento e da educação em saúde.

Desse modo, pré-ocupações já podem ser evidenciadas nas masculinidades dos homens, a partir da situação vivida pela pandemia, e na forma como passam a significar o seu vivido nesse período. Diante da compreensão de ser para a morte, a partir da alta mortalidade da doença e das notícias veiculadas pelas mídias, a produção, a criação e a transformação no mundo - Dasein - desses homens mobiliza-os para novas formas de ser no mundo, com abertura para possibilidades de autocuidado, implicando na organização de estratégias para assistir essas pessoas em suas necessidades ${ }^{(6)}$. Há, nesse cenário, novas relações de trocas existenciais e dialógicas, com uma interlocução necessária que, no âmbito da prática em saúde, se dará entre homens e profissionais de saúde ${ }^{(7)}$. Assim, quais são as implicações do "novo" cenário para o processo de cuidado?

Dessa maneira, a partir da compreensão das transformações, dos novos processos de cuidado em saúde de homens que são manifestados em um território social durante a pandemia, ancorados em pressupostos do existencialismo e do humanismo, desvelam-se subsídios essenciais para planejar ações e produzir cuidado, especialmente no campo da saúde pública, a fim de dar respostas eficazes, coerentes, sensíveis e qualificadas às necessidades e demandas individuais e comunitárias ${ }^{(7)}$.

Ancorados na necessidade de aprofundar de modo acurado sobre esse fenômeno de investigação que mobiliza os homens para o cuidado em saúde, este estudo pretendeu responder à questão: Como os homens significam a experiência vivida na pandemia da Covid-19? A fim de responder a tal inquietação, este artigo tem o seguinte objetivo: compreender os sentidos e significados atribuídos por homens ao período vivido na pandemia da Covid-19.

\section{MÉTODO}

\section{TIPO DO ESTUDO}

Trata-se de estudo qualitativo, estruturado nos conceitos da fenomenologia, embasada na interpretação heideggeriana $^{(8)}$. A ênfase recai sobre a revelação fenomenológica da experiência vivida, como possibilidade potencial de desvelar a ressignificação do modo de ser desses homens durante a pandemia.

As pesquisas de referencial fenomenológico na área da saúde $^{(9)}$, assim como na Enfermagem ${ }^{(10)}$, têm sido fortalecidas pela necessidade de apreensão dos significados próprios atribuídos por cada sujeito inserido em sua totalidade cultural e histórica.

\section{Cenário}

A produção de dados foi realizada nas cinco regiões do Brasil, de maneira não sequencial e consecutiva entre os distintos estados.

\section{CRITÉRIOS DE SELEÇÃo}

Foram incluídos os homens adultos e idosos que residiam no Brasil durante o período da coleta. Não foram incluídos os homens que se encontravam em trânsito em viagens internacionais.

O formulário foi organizado em duas partes: a primeira com questões relativas às características sociodemográficas e de saúde dos participantes; a segunda com questões abertas, relacionadas ao fenômeno investigado, para apreensão dos sentidos e significados atribuídos ao período vivido na pandemia. Tais questões são a seguir apresentadas: como você tem vivenciado a pandemia da Covid-19? A pandemia da Covid-19 trouxe-lhe alguma repercussão e/ou comprometimento? Caso tenha ocorrido alguma repercussão e/ou comprometimento, conte-nos o que você fez para superar tal ocorrido?

\section{DeFINIÇÃo DA AMOSTRA}

Participaram 400 homens. Frente ao contexto da pandemia, que impossibilita o emprego de métodos convencionais de coleta de dados, como a entrevista fenomenológica, a pesquisa foi realizada em ambiente virtual, a partir da disponibilização de um formulário hospedado no Google Forms, 
validado internamente pelos pesquisadores e ajustado externamente junto a um grupo de 20 homens.

A estratégia de seleção dos participantes ocorreu mediante a técnica de recrutamento consecutivo denominada snowbal(11), a partir da ampla divulgação do link de acesso ao formulário nas redes sociais digitais como Facebook, Instagram e WhatsApp.

\section{Coleta de dados}

A apreensão dos dados aconteceu entre abril e junho de 2020. As respostas enviadas pelos participantes foram exportadas e armazenadas automaticamente pelo programa, em planilha do Excel. Em seguida, foi realizada transferência dos dados para arquivos em formato Word, que foram organizados em pastas, com a utilização de códigos próprios, bem como senhas de acesso, com vistas a proteger os dados e evitar extravios e/ou perdas. Todo o processo foi realizado por doze pesquisadores com expertise na área, de maneira articulada.

\section{AnÁlise e TRATAMENTO DOS DADOS}

Os dados foram organizados e sistematizados após leitura linha a linha, processados e codificados no software NVIVO12, para apreensão das figuras metodológicas próprias do Discurso do Sujeito Coletivo (DSC) ${ }^{(12)}$. Considerou-se nesse processo de tratamento o verdadeiro aparente apreendido das respostas dos sujeitos, com as coerências, divergências e complementariedades dos elementos teóricos existentes no fenômeno ${ }^{(13)}$. Adotaram-se, como garantia de qualidade, as diretrizes do Consolidated Criteria for Reporting Qualitative Research - COREQ.

O DSC é um método indutivo que permite acessar a construção do pensamento coletivo e desvelar as generalidades sobre o fenômeno investigado. Com base no DSC, localizaram-se as expressões-chave e as ideias centrais e/ou ancoragens $^{(12)}$, as quais permitiram revelar as unidades de significados acomodadas em discursos-sínteses, compostas por subunidades sustentadas pelos sentidos e significados atribuídos pelos homens ao período vivido na pandemia da Covid-19 e as implicações para a Enfermagem. Tal representatividade coletiva revela-se nos discursos-sínteses, os quais foram interpretados à luz de elementos fenomenológicos heideggerianos ${ }^{(8)}$.

\section{AspeCtOS ÉTICOS}

O projeto foi aprovado pelo Comitê de Ética em Pesquisa (CEP), sob o parecer de número 4.076.529/2020, em conformidade com a Resolução n ${ }^{\circ} 466 / 2012$ do Conselho Nacional de Saúde. Foi disponibilizado aos participantes o link da página do projeto @cuidadoasaudedehomens, hospedado no Instagram, em que se ofertam intervenções de educação e comunicação em cuidado à saúde de homens. A página do projeto é um meio de divulgação de pesquisas e pode ser acessada a qualquer momento pelos participantes e comunidade em geral para acompanhar as informações e os conteúdos sobre saúde masculina.

\section{RESULTADOS}

Os homens participantes da pesquisa eram na maioria de identidade de gênero cisgênera $(330=82,5 \%)$, seguida por transgênera $(37=9,2 \%)$ e de identidade não-binária $(33=$ $8,2 \%)$. A identidade sexual mais prevalente foi a heterossexual $(162=40,5 \%)$, seguida de homossexual $(140=35,0 \%)$ bissexual $(98=24,5 \%)$. A maior parte dos homens tinha faixa etária entre 29 e 39 anos $(198=49,5 \%)$, autorreferiram a raça/cor predominante parda $(215=53,7 \%)$ e estado civil solteiro $(190=47,5 \%)$. Possuíam nível superior completo de escolaridade $(286=71,5 \%)$. A renda média declarada foi de mais de cinco salários mínimos $(175=43,7 \%)$, com a ocupação prevalente de servidores públicos $(107=26,7 \%)$. Conviviam com familiares (pais e/ou irmãos) $(107=26,7 \%)$, sendo a residência mais expressiva localizada na região Nordeste $(140=35,0 \%)$. Do total dos pesquisados, $21(5 \%)$ homens tiveram diagnósticos positivos para a Covid-19.

Ao dispor aos homens a oportunidade de refletirem sobre o período vivido na pandemia da Covid-19, desvelaram-se sentidos e significados atribuídos ao "novo" contexto, expondo inquietações surgidas nessa experiência, em dado momento da temporalidade, no qual a atualidade interfere em um novo porvir, a partir também de experiência do vigor de ter sido. Emergiram duas categorias de discursos-sínteses, sustentadas por suas ideias centrais que representam a coletividade do fenômeno investigado.

\section{UNIDADE DE SIGNIFICADO - DISCURSO- SÍNTESE 1: SER E ESTAR NO MUNDO NO CONTEXTO DA PANDEMIA VIVENCIANDO SUAS POSSIBILIDADES}

Compreendeu-se que esses homens vivenciaram o contexto da pandemia a partir das dimensões "ser" e "estar": a emocional e a temporal. Na dimensão "ser", o discurso do sujeito coletivo desvelou que os homens se angustiaram com as exigências de mudança do cotidiano simplesmente dado. $\mathrm{O}$ discurso demonstrou angústias permeadas por sentimento de impotência e emoções negativas pelo agravamento da situação, além do medo de ser contaminado e contaminar outras pessoas. A angústia pela situação imposta, associada com o medo da morte ao perceber a sua possibilidade, foi um aliado para que eles pudessem constituir novos sentidos e significados para a pandemia e as condutas necessárias para lançarem-se em outras possibilidades, frente às "pré-ocupações" expressas no cuidado.

\section{Subunidade - Ideia Central 1A: O vivido e A PERCEPÇÃO DO "ESTAR" NA PANDEMIA}

[...] primeiramente foi um grande susto para mim a chegada da
pandemia no meu país e na minha cidade. Foi estranho ver toda
a modificação das rotinas da minha cidade e presenciar, a cada
dia, o agravamento da situação com o avanço dos casos. Busquei
trabalhar mentalmente de que a pandemia era um problema
real que estava afetando todas as pessoas. Quando se tratava do
contágio e da exposição, e que eu não seria o único a ser afetado,
e pensando dessa maneira, passei a dar um novo significado ao
coronavirus è Covid-19 (DSC de homens). 
Sentimentos e emoções foram expressos e revelaram o temor e o receio frente à Covid-19, bem como a aceitação e o enfrentamento progressivo na busca pela minimização dos impactos deletérios ao bem-estar psicossocial provocado pela pandemia:

[...] tive ansiedade, preocupaçôes e tristeza, principalmente com as noticias de mortes que eram apresentadas nos jornais, que também estiveram relacionadas com o receio em ter familiares com doenças crônicas, o que me colocava em estado permanente de tensão. Tive medo do futuro. Depois veio a fase de aceitação, e passei a ficar mais tranquilo, evitando gerar grandes problemas como, por exemplo, a ansiedade, que já era algo que eu necessitava conviver. Tentar pensar com mais calma, na busca por não entrar em desespero, na busca por realizar atividades que me motivavam e que me faziam feliz, substituindo as atividades do trabalho e do agito do dia-a-dia, que foram interrompidas e, também, evitando pensar nos assuntos ruins relacionados à pandemia. Compreendi que se tratava de um periodo de risco à saúde de todos, e de um momento em que eu deveria me resguardar, adotar as medidas de prevenção e visar o bem comum (DSC de homens).

Os sentidos elaborados no vivido da pandemia marcam a experiência masculina diante do advento de uma nova doença, a qual promove preocupação, transformações sociais, econômicas, profissionais e culturais na vida humana. Compreendeu-se que, com o avanço da pandemia, revelado nas mídias, os homens passaram a ressignificar aquele momento. Os significados construídos revelaram uma mobilização, um novo modo de ser, para o estabelecimento de práticas de autoproteção individual e do "viver-melhor" coletivo.

\section{Subunidade - Ideia Central 1B: Angustiando-SE EM BUSCA DAS CLAREIRAS VISANDO UM "BEM-ESTAR" DURANTE A PANDEMIA}

Dimensões estruturais e conjunturais como o trabalho, a condição de mantenedor da família ou as atividades de lazer e afetivas permeiam a vivência cotidiana de homens de modo impróprio, sem que haja uma ocupação antecipada com a saúde, sendo modificadas na vivência da pandemia, expressas nas angústias, interações, relações e ações diante do "novo" presentes nos discursos. A busca pelo cuidado de si desvela o movimento em direção ao modo próprio do viver o cotidiano ao encontro de clareiras para novos modos de ser, visando o "bem-estar" masculino durante a pandemia da Covid-19:

[...] foram momentos que me levaram à reflexão sobre diversas condiçóes e fenômenos da minha vida como, por exemplo, as relaçôes interpessoais, o sistema econômico, as incertezas, os comportamentos e hábitos diante desse acontecimento. Para tanto, eu optei por me cercar de outros cuidados como, por exemplo, adequar-me ao isolamento social, adotar cuidados de higiene ao ir ao supermercado, farmácia ou outro serviço essencial, ajudar as pessoas no que fosse possivel, afastar os pensamentos ruins, assistir filmes, conviver melhor com a casa, cuidar do sono, cumprir demandas que estavam atrasadas, descansar, estabelecer contato virtual com as pessoas, exercitar a sabedoria e a perspectiva de animosidade para com o futuro, lidar com o desejo sexual, visto que a libido aparentava aumentar durante esse periodo, ocupar-
- me de tarefas que exigiam menor concentração mental e que me tiravam do foco da pandemia, ouvir músicas, pensar no cuidado de si, tomar conta de mim mesmo e usar técnicas de respiração para acalmar os batimentos cardíacos quando eu me sentia mentalmente afetado e, tudo isso, passou a me fazer sentir-se bem (DSC de homens).

\section{Subunidade - Ideia Central 1C: Construindo APRENDIZADOS PARA "SER-FAZER" ANTECIPADO E ALCANÇAR O "MELHOR-ESTAR" NA PANDEMIA}

Durante a pandemia, os homens refletiram sobre os sentidos dados aos seus modos de ser e fazer. Pensando na temporalidade em Heidegger, refletiram sobre o seu vigor de ter sido, para viver uma nova atualidade, com vistas a um porvir mais solidário. Nesse movimento, novos sentidos de ver e viver o mundo foram constituídos e conduziram ao encontro consigo mesmo, com a humanidade e com o cuidado não somente de si, mas também dos outros. Os aprendizados que se direcionam para um ser-fazer e para o encontro com o melhor-estar na pandemia a partir das vivências foram elucidados pelos homens:

[...] vivenciei momentos de reflexão sobre a minha vida. Estar passando por esse momento da pandemia tem representado uma oportunidade para compreender a importância do cuidado comigo e com o outro, não somente aqueles que estão próximos, mas as outras pessoas também, tentando aprender a dividir e compartilhar, e isso me fez sentir mais uitil, a exercitar a solidariedade e a empatia, afugentando também a melancolia e a saudade. Busquei seguir rigorosamente as recomendações para o controle da contaminação. Foi um momento de reclusão e autoconhecimento, pois passei a ver as situaçôes com maior clareza, passando a ser mais dono de mim, em relação a como enfrentar o virus e à Covid-19. Tudo isso me fez sentir aliviado e feliz por perceber que eu estava aos poucos conseguindo vencer os desafios. Tem representando também um respeito maior à humanidade, de repensar o meu papel em relação às pessoas e à família (DSC de homens).

\section{UNIDADE DE SIGNIFICADO - DISCURSOS-}

\section{SÍNTESE 2: O VIGOR DE TER SIDO E A ATUALIDADE}

\section{APRESENTAM-SE COMO POSSIBILIDADES DE UM NOVO}

"PORVIR" PARA ALÉM DA PANDEMIA

A angústia gerada por toda a situação trazida com a pandemia proporcionou um movimento de abertura para os homens reconsiderarem o seu modo de ser no mundo, a sua impropriedade. Assim, a abertura do ser para fora exterioriza a "pré-ocupação" relacionada à classe, política e cidadã, como também a existência de novas possibilidades ser.

\section{Subunidade - Ideia Central 2A: Ressignificando PARA "SER" E "MUDAR" DIANTE DA VIVÊNCIA DA PANDEMIA}

Os homens ressignificaram, no curso da pandemia, os modos de compreender o seu ser no mundo e expressaram o desenvolvimento de uma "pré-ocupação" com as questões de classe, cidadã e política: 
[...] não vivo a mesma realidade diária de antes, e imagino que as outras pessoas que moram nas favelas ou em bairros populares onde a violência impera devem ter sentido ainda mais mudanças com a chegada do coronavirus, que se tornou mais uma "desgraça" entre tantas outras existentes em nosso pais, que convive também com um Estado de exceção e desigualdade de privilégios (DSC de homens).

Subunidade - Ideia Central 2B: Elaborando novos SENTIDOS E SIGNIFICADOS PARA "TORNAR-SE" APÓS A VIVÊNCIA DA PANDEMIA

A compreensão da experiência vivida, determinada pelo discurso, direcionou o olhar de homens para o enfrentamento do que foi evitado, adiado. Os novos sentidos mobilizaram as certezas, atitudes e conviçcões, bem como o desejo de mudança, ao reconsiderarem as possibilidades de ser, oportunizar, aprender e amar para tornar-se melhor mediante a vivência da pandemia e os rompimentos e impactos causados por ela:

[...] com o surgimento da pandemia e todas as transformaçôes que ela causou em minha vida, me permiti pensar na possibilidade de desenvolver um relacionamento afetivo com outra pessoa. Repensei as minhas atitudes, as convicçôes, os propósitos e refleti sobre outros grupos sociais que estão vulneráveis e frágeis a esta nova doença. A pandemia se tornou um momento buscar novas oportunidades e aprendizados, e de tirar proveito do que foi positivo de todo momento difícil que eu vivi. Além disso, se mostrou um tempo de reconhecer a necessidade do autoamor e da superação das sensações de fracasso e, também, de aumentar e melhorar o meu contato com a esposa e filhos, de conversar mais com a familia e amigos, e me manter mais próximo das minhas redes sociais. Me posicionei social, econômica e politicamente diferente em relação à vida, em especial valorizar a vida e o próximo. A pandemia tem representado uma maneira nova de gerir a relação com as pessoas e também os meus medos e pensamentos, superação e compreensão do significado da pandemia como uma forma de construir os melhores caminhos na vida e as percepçóes sobre o futuro, de me sentir vivo e vitorioso em meio a esta crise, da qual eu estou convivendo, me adaptando, tendo resiliência, sempre com a esperança de haver um final positivo e continuar vivendo e sendo feliz (DSC de homens).

\section{DISCUSSÃO}

A coleta de dados foi realizada da ambiência virtual por meio da disponibilização de formulário online. Apesar de relevante número de participantes para a análise dessa temática, esse quantitativo destoante da abordagem fenomenológica limitou a análise do desvelamento da ontologia no círculo hermenêutico de forma mais aprofundada. Entre essas situações, destaca-se a falta da entrevista face a face por conta da necessidade de acesso às Tecnologias da Informação e Comunicação (TIC) para responder o formulário. Por essas razões, optamos por realizar um estudo com a utilização de alguns conceitos da fenomenologia.

Os discursos revelaram os modos de "ser" "estar" desses homens do mundo, face ao contexto da pandemia da Covid19 , no que concerne à sua historicidade e possibilidade de acessar medidas de cuidado ${ }^{(14)}$. Os participantes mostraram-se angustiados com a situação apresentada, percebendo-se como um ser para a morte. Por isso, revelaram-se em busca de clareiras que os levassem a novos modos de ser. Procuraram, assim, ressignificar a sua vida, buscando um estado de bem-estar, superação, reaproximação com a família, e solidariedade. Tal busca, entretanto, teve dificuldades, relacionadas à preocupação com a disseminação da doença, sua mortalidade, principalmente em familiares com doenças crônicas, e a situação de ter que lidar com o desejo sexual, visto que a libido aparentava aumentar durante esse período ${ }^{(2-3)}$.

Os homens desvelaram também, em seu discurso coletivo, que essas buscas por novos modos de ser tiveram relação com a sua temporalidade, visto que repensaram o seu vigor de ter sido, por meio de um encontro consigo a partir da situação da pandemia e da percepção de um ser para a morte, diante da mortalidade apresentada das mídias, ressignificando a sua atualidade, em busca de um novo porvir para além da pandemia. Nesse movimento, compreendeu-se que saíam da impropriedade cotidiana, atrás de modos próprios de ser, mediante a elaboração de novos sentidos e significados para a sua vida e das relações existentes entre o ser para a morte e as repercussões nos modos de ser dos homens, manifestadas com o advento da pandemia em seu país de residência.

Ao investigar as vivências masculinas no contexto pandêmico da Covid-19, o discurso coletivo desvelou o vivido e a percepção dos homens quanto ao "estar na pandemia". O ser e o estar no mundo explicitaram as possibilidades vivenciadas pelo masculino nesse cenário. Os homens compreenderam o estar no contexto da pandemia a partir de si próprios, do constituído dos seus afazeres, das modificações da rotina, do trabalho, dos sentimentos, das relações humanas envolvidas por um cenário de feitos que fazem parte da cotidianidade desse ser junto à sua própria organização do cotidiano. Desde que a Covid-19 passou a avançar entre os países, mudanças repentinas emergiram, e de maneira abrupta, impondo a adaptação de novos hábitos e comportamentos em grande parte da população global. Tal reconfiguração se deu porque repercussões negativas para a saúde e qualidade de vida foram pontuadas pela literatura, clamando por novos modos de viver ${ }^{(14-16)}$.

No âmbito das percepções dos homens sobre o estar na pandemia, compreendeu-se que a deflagração de sentimentos e emoções figurou os sinais fenomenológicos existentes, que tornaram apresentáveis os impactos negativos ocasionados ao bem-estar, principalmente o psicossocial e as estratégias de enfrentamento construídas e empregadas no cotidiano. Ao se surpreender com o isolamento, a alta mortalidade da doença, e estranhar todas as modificações impostas no cotidiano, o seu modo de ser foi interrogado e as incertezas apresentadas ao seu horizonte ${ }^{(15-17)}$ promoveram inquietações, sensações e sentimentos que alteraram o seu estado de saúde. Tal cenário provocou angústia, levando os homens a saírem da sua impropriedade, os quais reviram um novo modo de ser para a atualidade e o porvir, face à angústia e à sua abertura para novas possibilidades na vida. 
No contexto da pandemia, é possível inferir que os homens tiveram que lidar com o sentido presente nas vivências marcadas por um contexto de especificidade existencial $^{(18)}$. Em diversos cenários além do Brasil, como no Japão e Paquistão, foram observadas alterações comportamentais e psicossociais na população masculina no curso da pandemia, como alteração nos padrões de sono, hipervigilância, aumento do consumo alimentar e acesso a conteúdo na internet, elevação do estresse e tensão ${ }^{(17)}$. Outros estudos evidenciaram resultados positivos, na medida em que as pessoas conseguiram dar sentidos e significados para as suas vidas ${ }^{(18-21)}$.

Ao vivenciarem o "novo", os discursos explicitaram que, a partir da experiência do seu "ser-aí", foi possível apreender os sentidos elaborados pelos homens na vivência pandêmica da Covid-19 no Brasil. Preocupações e transformações da vida cotidiana marcaram tal experiência. As possibilidades de ser e estar são compreendidas como "elemento determinante do Dasein; as relações que ele estabelece a cada momento com o mundo em sua trajetória existencial, que apenas se completam com a morte" ${ }^{(8-15)}$. No sentido da fenomenologia heideggeriana, o estabelecimento das relações, o determinado momento e o mundo da pandemia em seu sentido existencial são modificados e ressignificados pelas possibilidades de angustiar-se e sair da cotidianidade, do impróprio.

Para autoproteger-se, os homens valeram-se de práticas individuais, íntimas e subjetivas, mas também aspiraram ter empregado práticas direcionadas ao "viver-melhor" na coletividade. É nesse cenário que o cuidado emerge como figuração existencial, o qual diz respeito tanto ao cuidado de si como ao "ser-com-outros", tendo em vista as maneiras de ocupar-se com o mundo mediante as suas próprias formas de $\operatorname{ser}^{(8-17)}$. Nesse âmbito, a clareira configura-se na dimensão prévia que possibilita o aparecer, o desocultamento ${ }^{(22)}$, o que permite explicar as mobilizações feitas pelos homens em torno do viver-melhor na pandemia, representado pelas práticas de cuidado biopsicossocial, de voltar às coisas mesmas, de repensar o sentido do ser e a compreensão de si para fortalecer e transformar.

Comportamentos similares aos adotados pelos homens neste estudo, na tentativa de enfrentar a pandemia, foram identificados e recomendados em investigação realizada com 5.545 indivíduos adultos na Espanha ${ }^{(23-24)}$. Nesse estudo, os achados relevaram a adoção de estratégias baseadas em atitudes positivas, com perspectivas existencialistas a partir da preocupação consigo mesmo, com os sentidos da vida e com a humanidade.

Com base nessas informações, enfermeiras e sua equipe podem sutilmente localizar os caminhos que estão sendo utilizados pelos homens para lidarem com a pandemia, estabelecendo estratégias de um cuidado integral e mais humano. Diante das dificuldades dos homens em lidar com o autocuidado de saúde e a abertura trazida pela pandemia para a possibilidade deles cuidarem melhor de sua saúde, as estratégias podem ser conduzidas pela Enfermagem como clareira para pensar o cuidado próprio para homens.

Ao buscarem manter-se em bem-estar no curso da pandemia em seu país, os homens expuseram as suas angústias e as tentativas de encontrar as clareiras, que, por sua vez, permitiram conduzi-los a um espaço de reflexão, de olhar para si e para as condições da vida. As angústias experienciadas podem ter sido geradoras de incômodos, provocando movimentos de (re)olhar as coisas no chamado "novo normal"(25). Nesse ínterim, o discurso masculino revelou a revisão de atitudes, comportamentos, mudanças de hábitos, adequações, que ora parece estar mobilizada pela imposição do confinamento, ora parece ser um exercício direcionado ao cuidado de si.

É relevante destacar que no território latino-americano, principalmente no Brasil, os modelos de masculinidades são fortemente estruturados na hegemonia patriarcal, com expressiva influência do machismo. Como consequência, atributos como tolher sentimentos e imprimir excessivamente a força, a virilidade e a honra são considerados como essenciais à construção social das masculinidades. Nesse sentido, o lugar da sentimentalidade, da fala, da expressão das emoções estará posto à margem, encoberto, o que pode implicar na dificuldade dos homens em colocar as questões que lhes afligem.

É imprescindível destacar que o campo da sensibilidade está intrínseco ao fazer e à produção do cuidado em Enfermagem, o que faz requerer dos profissionais o aguçamento para o emprego do cuidado sensível, o acolhimento e a escuta qualificada ${ }^{(26)}$, a fim de captar e se ocupar com aquilo que os homens estão trazendo enquanto demandas, necessidades e, até, mesmo, daquilo que não foi posto e o que está encoberto.

A compreensão dos discursos tornou possível reconhecer que os homens se mobilizaram para o "ser-fazer", que se configura, no pensamento heideggeriano, no aprendizado a partir do fazer, da experimentação e também para alcançar o "melhor-estar", conferindo o ser como possibilidade. O apreendido da pandemia tem sido significativo, de modo a promover transformações no modo de ser de homens, modificando o seu porvir ${ }^{(27)}$. O discurso masculino desvela as aspirações dos novos sentidos de ver e viver o mundo, as relações consigo mesmo, a vida e a humanidade.

$\mathrm{O}$ acolhimento em si da transformação, assim como a manutenção da identidade do ser homem, tem aparentado estar em transformação também, o que pode configurar uma elaboração fenomenológica sobre o contexto pandêmico e os modos de viver a vida ${ }^{(28)}$. Nota-se que as pessoas vivem de modo impróprio no cotidiano, sem darem valor às coisas, tal como pode estar ocorrendo com a vida masculina, que costumeiramente tem sido compreendida por grande parte dos homens como uma coisa dada nos modos de ser em sua historicidade. O cenário da pandemia parece romper com os modos impróprios de ser dos homens, provocando e propiciando a abertura para novos modos de ser.

Para o olhar fenomenológico, a reflexão que se busca fazer está direcionada para diversas condições e fenômenos da vida, com a motivação de ajudar as pessoas naquilo que for possível. Dessa maneira, seus pressupostos permitiram localizar, nos resultados, a coexistência dos cuidados de si e aos outros dos homens no contexto complexo da pandemia da Covid-19. Esse cenário explicita relevante implicação 
para a Enfermagem na medida em que elucida as práticas de cuidado masculino, muitas vezes sutis, encobertas e até mesmo invisíveis em outros cenários, possibilitando que enfermeiras e sua equipe acolham, valorizem, investiguem e teçam intervenções sobre esse cuidado.

Implicações valiosas dessas ressignificações são reconhecidas para o processo de trabalho e a produção do cuidado em saúde pública, que, por meio dessas evidências, podem reconhecer de maneira mais acurada os fenômenos geradores de repercussões negativas e as significações positivas presentes nas vivências dos homens, principalmente em tempos em que se buscam explicações para o caos ${ }^{(29)}$. Nesse sentido, é importante reconhecer que grupos de homens circunscritos em contextos de vulnerabilidades sociais, atravessados por barreiras de classe social, minoria de gênero, sexualidade e raça/cor, poderão enfrentar situações distintas no contexto pandêmico da Covid-19, o que requer uma atenção de Enfermagem específica e compatível com as demandas emergidas desses atravessamentos macroestruturais e interseccionais.

\section{CONCLUSÃO}

Os sentidos e significados atribuídos por homens ao período vivido na pandemia da Covid-19 revelaram um estar no contexto da pandemia a partir deles próprios com modificações da rotina, dos sentimentos e do abrir-se à novas possibilidades e transformações, o que gerou impactos psicossociais e estratégias de enfrentamento e de cuidado nesse período. As incertezas provocaram inquietações e as preocupações culminaram em autoproteção por meio da adoção de práticas individuais e coletivas para "viver-melhor". Desse modo, os homens estão na abertura para refletir, olhar para si e para as condições da vida, buscando o cuidado biopsicossocial, com evidentes transformações na identidade do ser homem e nas suas masculinidades.

Essa compreensão incide em implicações para a saúde, e em especial para a Enfermagem. Assim, é importante para a Enfermagem compreender as masculinidades, identidades, e, consequentemente, rever práticas de cuidado que precisam dar conta das necessidades de saúde que esse público solicita, o que requer adaptações nos serviços (estruturais e humanas) para atender tais necessidades. Destaca-se que o ser-homem, ao ampliar sua compreensão no mundo, alargar suas estratégias de enfrentamento dos desafios da vida, bem como do se cuidar e do cuidar dos outros, precisa encontrar nos serviços de saúde profissionais que atendam suas necessidades, com entendimento não somente na perspectiva cultural e histórica como fortes e invencíveis, mas também como dotados de vicissitudes, angústias, inquietações, que sofrem e sentem dor.

\section{RESUMO}

Objetivo: Compreender os sentidos e significados atribuídos por homens ao período vivido na pandemia da Covid-19. Método: Estudo qualitativo estruturado nos conceitos da fenomenologia, embasada na interpretação ôntica heideggeriana, realizado com 400 homens residentes no Brasil. A produção de dados foi por meio de um formulário disponibilizado online. As respostas foram processadas no software NVIVO12 e analisadas segundo o discurso do sujeito coletivo. Resultados: Emergiram duas unidades de significados analíticos acomodados em discursos-sínteses, sustentadas por ideias centrais, ordenadas em cinco subunidades que representam a coletividade do fenômeno investigado, quais sejam: Ser e estar no mundo no contexto da pandemia vivenciando suas possibilidades e $O$ vigor de ter sido e a atualidade se apresentam como possibilidades de um novo "porvir" para além da pandemia. Conclusão: Os sentidos e significados revelaram um estar no contexto da pandemia a partir deles próprios com modificações da rotina, dos sentimentos e do abrir-se à novas possibilidades e transformações, o que gerou impactos psicossociais e estratégias de enfrentamento e cuidado no período do processo pandêmico. Como implicações, há que se ter uma nova compreensão do ser-homem, pois demonstrou precisar de cuidado, o qual está para além do físico.

\section{DESCRITORES}

Pandemias; Covid-19; Saúde do Homem; Existencialismo; Humanismo; Enfermagem.

\section{RESUMEN}

Objetivo: Comprender los sentidos y significados atribuidos por hombres al período vivido en la pandemia de Covid-19. Método: Es un estudio cualitativo estructurado a partir de los conceptos de la fenomenología, basado en la interpretación óntica heideggeriana, realizado con 400 hombres residentes en Brasil. La producción de datos se realizó con un formulario disponible en línea. Las respuestas se procesaron en el programa informático NVIVO12 y se analizaron según el discurso del sujeto colectivo. Resultados: Surgieron dos unidades de significados analíticos acomodados en síntesis discursivas, apoyadas en ideas centrales, organizadas en cinco subunidades que representan la colectividad del fenómeno investigado, a saber: Ser y estar en el mundo en el contexto de la pandemia, experimentando sus posibilidades y El vigor de haber sido y la actualidad se presentan como posibilidades de un nuevo "porvenir" más allá de la pandemia. Conclusión: Los sentidos y significados revelaron un estar en el contexto de la pandemia a partir de ellos mismos con modificaciones de la rutina, de los sentimientos y la apertura a nuevas posibilidades y transformaciones, lo que generó impactos psicosociales y estrategias de afrontamiento y cuidado en el período del proceso pandémico. Como implicaciones, es necesario entender al ser-hombre desde una nueva perspectiva, ya que ha quedado demostrado que necesita cuidados más allá de lo físico.

\section{DESCRIPTORES}

Pandemias; Covid-19; Salud del Hombre; Existencialismo; Humanismo; Enfermería.

\section{REFERÊNCIAS}

1. Ahmed, Z, Ahmed, O, Aibao, Z, Hanbin, S, Siyu L, Ahmad A. Epidemic of COVID-19 in China and associated psychological problems. Asian J Psychiatr. 2020;2020;51:102092. https://doi.org/10.1016/j.ajp.2020.102092

2. Barreto ML, Barros AJ, Carvalho MS, Codeço CT, Hallal PR, Medronho RA, et al. [What is urgent and necessary to inform policies to deal with the COVID-19 pandemic in Brazil?] Rev Bras Epidemiol. 2020;23:e200032. Portuguese. https://doi.org/10.1590/1980-549720200032 
3. Griffith DM, Sharma G, Holliday CS, Enyia OK, Valliere M, Semlow AR, et al. Men and COVID-19: a biopsychosocial approach to understanding sex differences in mortality and recommendations for practice and policy interventions. Prev Chronic Dis. 2020;17:E63. https://doi.org/10.5888/pcd17.200247

4. Rozenberg S, Vandromme J, Martin C. Are we equal in adversity? Does Covid-19 affect women and men differently? Maturitas. 2020;138:62-8. https://doi.org/10.1016/j.maturitas.2020.05.009

5. Bwire GM. Coronavirus: why men are more vulnerable to Covid-19 than women? SN Compr Clin Med. 2020;4(7):1-3. https://doi.org/10.1007/s42399-020-00341-w

6. Sousa AR, Silva NS, Lopes S, Rezende MF, Queiroz AM. Expressions of masculinity in men's health care in the context of the COVID-19 pandemic. Rev Cuba Enferm [Internet]. 2020 [cited 2020 Apr 3];36:e3855. Available from: http://www.revenfermeria.sld.cu/index.php/ enf/article/view/3855/608

7. Paterson JG, Zderad LT. Enfermagem humanística. New York: National League for Nursing; 1988.

8. Heidegger M. Ser e tempo. Campinas: Editora da Unicamp, Petrópolis: Vozes; 2020.

9. González AD, Garanhani ML, Bortoletto MS. Almeida MaJ, Melchior R, Nunes EFPA. [Heidegger's phenomenology as a framework for health education studies]. Interface (Botucatu). 2012;16(42):809-17. Portuguese. https://doi.org/10.1590/S1414-32832012005000035

10. Souza MA, Cabeça LP, Melo LL. [Nursing research supported by the phenomenological framework of Martin Heidegger]. Av Enferm. 2018;36(2):230-7. Portuguese. https://doi.org/10.15446/av.enferm.v36n2.67179

11. Patias ND, Von Hohendorff J. Quality criteria for qualitative research articles. Psicol Estud. 2019;24:e43536. https://doi.org/10.4025/ psicolestud.v24i 0.43536

12. Lefevre F, Lefevre AM. Discourse of the collective subject: social representations and communication interventions. Texto Contexto Enferm. 2014;23(2):502-7. https://doi.org/10.1590/0104-07072014000000014

13. Nascimento LC, Souza TV, Oliveira IC, Moraes JR, Aguiar RC, Silva LF. Theoretical saturation in qualitative research: an experience report in interview with schoolchildren. Rev Bras Enferm. 2018;71(1):228-33. https://doi.org/10.1590/0034-7167-2016-0616

14. Tabish SA. COVID-19 pandemic: emerging perspectives and future trends. J Public Health Res. 2020;9(1):1786. https://doi.org/10.4081/ jphr.2020.1786

15. Braga TB, Farinha MG. [Heidegger: searching for sense for the human existence]. Rev Abordagem Gestalt [internet]. 2017 [cited 2020 Set];23(1):65-73. Portuguese. Available from: http://pepsic.bvsalud.org/pdf/rag/v23n1/v23n1a08.pdf

16. Xiang YT, Yang Y, Li W, Zhang L, Zhang Q, Cheung T, et al. Timely mental health care for the 2019 novel coronavirus outbreak is urgently needed. Lancet Psychiatry. 2020;7(3):228-9. https://doi.org/10.1016/S2215-0366(20)30046-8

17. Sousa AR, Carvalho ES, Santana TS, Sousa ÁF, Figueiredo TF, Escobar OJ, et al. Men's feelings and emotions in the Covid-19 framing. Cienc Saúde Coletiva. 2020;25(9):3481-91. https://doi.org/10.1590/1413-81232020259.18772020

18. Critelli DM. Analítica do sentido: uma aproximação e interpretação do real de orientação fenomenológica. 2th. ed.. São Paulo: Brasiliense; 2016.

19. Ferreira LD, Angelim DA, Sabóia RR, Demes Cl, Carvalho CS, Nigri Flávia Maria Noronha NF, et al. Covid-19 in the State of Ceará: behaviors and beliefs in the arrival of the pandemic. Cienc Saúde Coletiva.2020;25(5):1575-86. https://doi.org/10.1590/141381232020255.07192020

20. Muacevic A, Adler JR, Balkhi F, Nasir A, Zehra A, Riaz R. Psychological and behavioral response to the Coronavirus (COVID-19) pandemic. Cureus. 2020;12(5):e7923. https://doi.org/10.7759/cureus.7923

21. Parady G, Taniguchi A, Takami K. Travel behavior changes during the COVID-19 pandemic in Japan: analyzingthe effects of risk perception and social influence on going-out self-restriction. Transp ResInterdiscip Perspect. 2020;7:1001812. https://doi.org/10.1016/j. trip.2020.100181

22. Ribeiro AA. [From the unveiling to the clearing: the development of the notion of truth in Heidegger]. Controvérsia [internet]. 2018 [cited 2020 Sep 3];14(2):17-24. Portuguese. Available from: http://revistas.unisinos.br/index.php/controversia/article/view/15995

23. Fullana MA, Hidalgo-Mazzei D, Vieta E, Radua J. Coping behaviors associated with decreased anxiety and depressive symptoms during the COVID-19 pandemic and lockdown. J Affect Disord. 2020;275:80-1. https://doi.org/10.1016/j.jad.2020.06.027

24. Zanon C, Dellazzana-Zanon LL, Wechsler SM, Fabretti RR, Rocha KN. [COVID-19: implications and applications of Positive Psychology in times of pandemic]. Estud Psicol (Campinas). 2020;37:e200072. https://doi.org/10.1590/1982-0275202037e200072

25. Cahapay MB. Stranded College students amid Corona Virus Disease 2019 pandemic: an existential phenomenology. J Loss Trauma. 2020;25(6-7):598-604. https://doi.org/10.1080/15325024.2020.1770955

26. Lopes SS, Cruz SL. [Recognizing listening as a therapeutic resource in the care for women's health]. Rev Psicol Saúde. 2019;11(1):19-42. Portuguese. https://doi.org/10.20435/pssa.v0i0.571

27. Oliveira AC, Lucas Thabata C, Iquiapaza RA. What has the Covid-19 pandemic taught us about adopting preventive measures? Texto Contexto Enferm. 2020;29:e20200106. https://doi.org/10.1590/1980-265x-tce-2020-0106

28. Connell RW, Messerschmidt JW. Hegemonic masculinity: rethinking the concept. Rev Estud Fem. 2013;21(1):241-82. Portuguese. https://doi.org/10.1590/S0104-026X2013000100014

29. Camargo KR Jr. Trying to make sense out of chaos: science, politics and the COVID-19 pandemic. Cad Saude Publica. 2020;36(4):e00088120. https://doi.org/10.1590/0102-311x00088120 